\title{
Políticas Públicas para a Fronteira Brasileira: Regulação, mecanismos e ações de segurança e Defesa Nacional
}

\author{
Public Policies for the Brazilian Border: Regulation, mechanisms and security and Defense Actions \\ Políticas Públicas para la Frontera Brasileña: Regulación, mecanismos y acciones de Seguridad Y
}

Defensa

Recebido: 06/07/2021 | Revisado: 10/07/2021 | Aceito: 12/07/2021 | Publicado: 22/07/2021

Nedisson Luis Gessi

ORCID: https://orcid.org/0000-0002-4508-2826

Fundação Educacional Machado de Assis, Brasil

E-mail: nedisson@fema.com.br

Sérgio Luís Allebrandt

ORCID: https://orcid.org/0000-0002-2590-6226

Universidade Regional do Noroeste do Estado do Rio Grande do Sul, Brasil

E-mail: allebr@unijui.edu.br

Nelson José Thesing

ORCID: https://orcid.org/0000-0001-7123-0717

Universidade Regional do Noroeste do Estado do Rio Grande do Sul, Brasil

E-mail: nelson.thesing@unijui.edu.br

Airton Adelar Mueller

ORCID: https://orcid.org/0000-0001-6270-5856

Universidade Regional do Noroeste do Estado do Rio Grande do Sul, Brasil

E-mail: airton.mueller@unijui.edu.br

Magalia Gloger dos Santos Almeida

ORCID: https://orcid.org/0000-0002-9314-4016

Universidade Regional do Noroeste do Estado do Rio Grande do Sul, Brasil

E-mail: magalia.almeida@ sou.unijui.edu.br

Melissa Welter Vargas

ORCID: https://orcid.org/0000-0002-0169-3246

Universidade Regional do Noroeste do Estado do Rio Grande do Sul, Brasil

E-mail: melissa.vargas@ sou.unijui.edu.br

\begin{abstract}
Resumo
Em face de tamanha relevância da Faixa de Fronteira, como área estratégica para a soberania do país, o objetivo do presente estudo é analisar as políticas, programas e ações do governo federal, referentes à segurança nacional, à defesa e repercussões na Faixa de Fronteira. Para além de apontar um arcabouço normativo constitucional e infraconstitucional no tocante à fronteira brasileira, a pesquisa conta com abordagem qualitativa, exploratória, descritiva, documental e bibliográfica, para compreender as repercussões, as ações de segurança e defesa, na Faixa de Fronteira brasileira, os mecanismos políticos-institucionais, tendo presente a base normativa do Centro de Documentação e Informação da Câmara dos Deputados, na Rede de Informação Legislativa e Jurídica. Os achados da pesquisa evidenciaram a necessidade da atualização, de modernização da base normativa das áreas de fronteira, que por ora apresentam um elevado grau de desarticulação, com enormes dificuldades para identificar as políticas governamentais, perante as fronteiras do Brasil, o que gera pouca participação da população no processo, bem como, percebe-se dificuldades de integração e políticas conjuntas, em boa parte, pelas legislações que inibem as implementações de vetores de cooperação e integração com os países vizinhos, contribuindo para o enfraquecimento da visão de desenvolvimento regional.

Palavras-chave: Fronteira; Segurança; Defesa nacional; Base normativa; Políticas públicas.
\end{abstract}

\begin{abstract}
Given the importance of the Border Strip as a strategic area for the country's sovereignty, the objective of this study is to analyze the federal government's policies, programs and actions, related to national security, defense and repercussions in the Border Strip. In addition to pointing out a constitutional and infra-constitutional normative framework regarding the Brazilian border, the research has a qualitative, exploratory, descriptive, documentary and bibliographic approach, to understand the repercussions, security and defense actions, in the Brazilian Border Strip, the political-institutional mechanisms, bearing in mind the normative basis of the Documentation and Information Center of the Chamber of Deputies, in the Legislative and Legal Information Network. The research findings evidenced the need to update, modernize the normative basis of the border areas, which for the time being present a high degree of disarticulation, with enormous difficulties in identifying government policies, before the borders of Brazil, which
\end{abstract}


generates little participation of the population in the process, as well as, there are difficulties in integration and joint policies, in large part, due to legislation that inhibits the implementation of vectors of cooperation and integration with neighboring countries, contributing to the weakening of the vision of regional development.

Keywords: Border; Safety; National defense; Normative basis; Public policy.

\section{Resumen}

Dada la importancia de la Franja Fronteriza, como área estratégica para la soberanía del país, el objetivo de este estudio es analizar las políticas, programas y acciones del gobierno federal relacionados con la seguridad nacional, defensa y repercusiones en la Franja Fronteriza. Además de señalar un marco normativo constitucional e infraconstitucional sobre la frontera brasileña, la investigación tiene un enfoque cualitativo, exploratorio, descriptivo, documental y bibliográfico, para comprender las repercusiones, acciones de seguridad y defensa, en la Franja Fronteriza Brasileña, el Mecanismos político-institucionales, teniendo en cuenta la base normativa del Centro de Documentación e Información de la Cámara de Diputados, en la Red de Información Legislativa y Jurídica. Los hallazgos de la investigación evidenciaron la necesidad de actualizar, modernizar la base normativa de las zonas fronterizas, que por el momento presentan un alto grado de desarticulación, con enormes dificultades para identificar políticas de gobierno, ante las fronteras de Brasil, lo que genera poca participación de la población en el proceso, así como, existen dificultades en la integración y políticas conjuntas, en gran parte, debido a una legislación que inhibe la implementación de vectores de cooperación e integración con los países vecinos, contribuyendo a debilitar la visión de desarrollo regional.

Palabras clave: Fronteriza; Seguridad; Defensa nacional; Base normativa; Políticas públicas.

\section{Introdução}

A sociedade, nas últimas décadas, conquistou grandes avanços científicos e tecnológicos, nos diversos serviços, processos e produtos, implantando um ambiente complexo que aponta vários desafios no campo da articulação, especialmente nas políticas de desenvolvimento local e políticas de segurança. Um movimento que contempla um grande conjunto de atores, das mais variadas escalas, níveis federativos, o que remete para um olhar histórico de como o Brasil trata essa questão. No início do século XIX até fins dos anos 1990, período que deu início à delimitação territorial brasileira, as fronteiras mantiveram-se como foco primordial de políticas de segurança nacional.

Vale destacar que a primeira legislação a tratar da questão, a Lei nº 601 de 1890, considerava a fronteira como uma área de segurança nacional e estabelecia uma faixa de dez léguas de todo o território nacional. Ao observar a evolução normativa da Faixa de Fronteira brasileira, que variou ao longo da história de 66 km (dez léguas), 100 km e 150 km, verifica-se que sempre houve uma estrutura de governo atuante nas áreas de fronteira. Ou seja, desde o Império, a ocupação da Faixa de Fronteira se deu por órgãos governamentais: no Governo Imperial, pela Diretoria Geral de Terras Públicas, posteriormente pelo Conselho Superior de Segurança Nacional, mais tarde pelo Conselho Nacional de Segurança e, atualmente, pelo Conselho de Defesa Nacional.

Portanto, historicamente, a ação governamental para as regiões de fronteira oscila entre políticas com foco na soberania nacional e no desenvolvimento local. No entanto, o Brasil tem tentado equalizar essa dicotomia, a complexidade das demandas tem crescido, afetando a condução de políticas de segurança, defesa e desenvolvimento. Assim, diante desse contexto, a pesquisa apresenta a seguinte problemática: Qual a contribuição da base normativa nacional para a interação entre segurança e desenvolvimento, bem como, esse processo tem contribuído para o desenho de políticas públicas de segurança e desenvolvimento na Faixa de Fronteira?

Por fim, percebe-se que há na legislação brasileira, especificamente referente à Faixa de Fronteira, áreas indispensáveis à segurança nacional, uma atenção especial ao acompanhamento da presença estrangeira e ao desenvolvimento de atividades consideradas estratégicas. Desta forma, o objetivo do estudo é analisar os programas e ações do Governo Federal, referentes à segurança nacional, à defesa e suas repercussões na Faixa de Fronteira, além de apontar o arcabouço normativo constitucional e infraconstitucional no tocante à fronteira brasileira. 


\section{Metodologia}

A pesquisa é um procedimento racional e sistemático, que tem por objetivo apresentar respostas aos problemas propostos, que contam com informações insuficientes frente à realidade (Gil, 2008). Portanto, os caminhos metodológicos contemplam o levantamento bibliográfico e documental acerca das repercussões dos programas e ações de segurança e defesa e seus impactos na faixa de fronteira brasileira, bem como, os mecanismos políticos-institucionais, além de uma pesquisa exploratória e descritiva na base normativa do Centro de Documentação e Informação (CEDI) da Câmara dos Deputados na base LexML - uma Rede de Informação Legislativa e Jurídica.

Assim, a trilha de pesquisa conta com a abordagem qualitativa, que permite um estudo amplo, que contempla um rico arcabouço, uma complexa rede de termos, conceitos e suposições, relacionados aos estudos culturais, repercussões de programas, políticos institucionais, como mecanismo de interpretação (Denzin; Lincoln, 2006). Já Minayo (1994), corrobora esta linha de investigação, ao afirmar que a pesquisa qualitativa, responde a questões muito particulares, com um nível de realidade que não pode ser quantificado e, sim, exposto e interpretado pelos próprios pesquisados.

No entanto, é pertinente ter presente que as abordagens qualitativas oportunizam estudos que mergulham em campos epistemológicos. Para González Rey, (2005), o caminho da epistemologia faz compreender que a pesquisa necessita de um processo permanente da produção de ideias. Esse processo é enriquecido pelos pesquisadores, ao organizarem os cenários complexos, ao verificarem os caminhos históricos dos objetos de estudos, para assim auxiliar em respostas, frente às necessidades das pesquisas, não em um processo linear e, sim, em um processo onde os pesquisadores assumem um papel ativo no desenvolvimento da pesquisa.

Por conseguinte, o estudo opera em um campo descritivo, em base bibliográfica e documental, permeando os caminhos das ações de segurança e defesa, os impactos na faixa de fronteira brasileira, bem como os mecanismos políticos-institucionais, com o objetivo de proporcionar visão geral acerca do objeto de estudo (Gil, 2014). Para além, conta com a pesquisa exploratória e descritiva para proporcionar maior familiaridade com o estudo, por meio de levantamento bibliográfico e documental (Gil, 2008).

\section{Resultados e Discussão}

Inicialmente, a pesquisa aponta a necessária compreensão acerca de conceitos como Estado, Nação, Estado-Nação, Soberania e Fronteira, que, por vezes, se confundem e são de extrema pertinência para a compreensão das dinâmicas nas ações, programas e políticas públicas para a Faixa de Fronteira brasileira. Pois é na fronteira, onde os Países dividem seus territórios, que um contingente populacional cuja história social é marcada historicamente por contatos interculturais que permitem pensar os mecanismos de interação social e relações interétnicas (Silva \& Lalane, 2019; Cf. Silva, 2016; 2019)

Segundo Scherma (2015b), o Estado surgiu e se consolidou na Europa entre os séculos XIII e XIX, já se apresentando no XVII como modelo de organização política dominante, no conjunto das relações socioeconômicas, de tal forma que, entre o final do século XV e o início do XVII, começam a se definir os contornos do moderno sistema político internacional. Assim, vários teóricos buscam uma melhor definição de Estado, seu surgimento e sua relevância, principalmente os atrelados à Ciência Política, como Mann (1992); Tilly (1996) e Weber (2009).

Tem-se presente que o sociólogo alemão Weber, pelos seus estudos sobre o Estado, tornou-se uma das autoridades mais importantes, ao apontar que o território geográfico, a partir da formulação de Leis, da fiscalização, do cumprimento das mesmas, contempla os caminhos pelo monopólio dos meios de coerção física (Weber, 2009).

Ao buscar a compreensão do conceito de Nação, a interpretação torna-se complexa, dada a dificuldade ao separar noções como "identidade" e "cultura", uma vez que, essas terminologias fazem parte de uma mesma trama simbólica. "As identidades 
nacionais não são coisas com as quais nós nascemos, mas são formadas e transformadas no interior da representação" (Hall, 2001, p.48).

Assim, a Nação "não é apenas uma entidade política, mas algo que produz sentidos - um sistema de representação cultural. As pessoas não são apenas cidadãos legais de uma nação; participam da ideia da nação tal como representada em sua cultura nacional” (Hall 2001, p.49). O fato de a nação não ser apenas uma entidade política, talvez tenha sido a causa do grande pecado do "nacionalismo" uma vez que, este submeteu os aspectos culturais aos fins políticos, quando não aos econômicos, cujos reflexos ainda se fazem sentir na história recente do mundo, com as "xenofobias e políticas de identidade" (Hobsbawn \& Ranger, 1995).

Segundo Hall (2001), as culturas nacionais são compostas não apenas de instituições culturais, mas, também, de símbolos e representações. Uma cultura nacional é um discurso - um modo de construir sentidos que influencia e organiza tanto nossas ações quanto a concepção que temos de nós mesmos. E o discurso, portanto, tem importância fundamental na articulação dessa comunhão de anônimos, discurso este que ressalta as diferenças entre os grupos, momento em que o nacionalismo substitui o sentimento nacional e fomenta a unidade nacional. Mas, não aquela unidade idealizada ainda nos tempos modernos, mas a unidade da diversidade, incluindo todos os segmentos e etnias, configurando a diferença cultural (Bhabha, 2001).

Por consequência, a nação é também "imaginada como soberana, porque o conceito nasceu numa época em que o Iluminismo e a Revolução estavam destruindo a legitimidade do reino dinástico hierárquico, devidamente instituído" (Anderson, 1989, p.15). A soberania talvez seja o vetor mais polêmico da nação. Pois, não existe nação que não seja soberana, uma vez que, esta não perece junto com o Estado quando este acaba. Entende-se então, a expressão soberania nacional como um pleonasmo (Burgardt, 2012).

Outro aspecto importante é a definição dos limites da nação. "A nação é imaginada como limitada, porque até mesmo a maior delas, que abarca talvez um bilhão de seres humanos, possui fronteiras finitas, ainda que elásticas, para além das quais se encontram outras nações" (Anderson, 1989, p.15). A limitação de uma fronteira, apesar de ser elástica, nos mostra a impossibilidade de se acatar a ideia da nação como constitutiva do Estado. Entretanto, é mais fácil admitir o contrário: o Estado é que faz parte da nação, pois independente do modelo de sociedade política adotada por um povo, são os valores deste povo que irão definir o modelo de ente estatal que melhor the aprouver (Burgardt, 2012).

Assim, a existência de um território delimitado é condição sine qua non para a existência de uma nação. É a chamada dinâmica cultural que, além de promover a manifestação dos mesmos aspectos culturais, em diferentes partes, responsabiliza-se pela sua transformação, o que, ao invés de representar um perigo, enriquece o conjunto cultural nacional, ao tempo que o expande. Portanto, a Nação é uma sociedade politicamente organizada, que compartilha uma história e um destino comum e conta com um território e um Estado para, assim, formar um Estado-Nação (Silva \& Tourinho, 2018; Silva \& Svartman, 2019).

A história do surgimento do Estado moderno e da formação do Estado-Nação é uma história de grandes lutas políticas. O Estado moderno nasceu no norte da Itália, no século XIV, com as cidades-estados governadas como repúblicas, quando começa a revolução capitalista. Os Estados-Nação nasceram mais tarde, na França e na Inglaterra, em torno das monarquias absolutas, que se constituíram na Europa depois da revolução comercial, da emergência de uma burguesia associada ao monarca absoluto, das lutas fratricidas que se sucederam à Reforma. Os tratados de Vestefália são, geralmente, identificados com o momento do surgimento do Estado-Nação. O Estado moderno é, portanto, o resultado da formação dos Estados-Nação e da Revolução Industrial (Bresser-Pereira, 2017).

Já no tocante à soberania, para Beaulac (2003), foi Jean Bodin, o "pai” da soberania, que realizou a primeira discussão sistemática sobre a natureza dessa palavra. Para Bodin (1992), a soberania é indivisível, o poder soberano centra-se em última instância, na comunidade política. Portanto, somente os Estados possuem a prerrogativa legal para agir em suas fronteiras, sem 
a interferência de outras forças, sejam elas internas ou externas, o que oportuniza a presença de características marcantes da soberania, da capacidade de fazer leis (Granato, 2018).

No contexto das fronteiras no século XXI, percebe-se um movimento onde o Estado se retira de sua função de proteção e reaparece no papel de controle e regulação. Em outras palavras, pode-se estar assistindo mais do que uma "desterritorialização" generalizada, mas à substituição de um modelo de territorialização por outro (Grimson, 2000). Por consequência, para ampliar o conceito de fronteira, é aconselhável fazer o uso da geografia ou, mais precisamente, da geopolítica, disciplina que tem a relação mais intrínseca com o tema e que, portanto, tem sido a fonte conceitual para muitos Policy Maker quando o assunto é fronteira.

Portanto, a palavra fronteira não é uma palavra neutra. Suscita sentimentos e valores diferentes. Mas ela é, também, uma palavra descritiva, designa o lugar de início ou de fim: início de um Estado, ou fim de outro Estado. Numa linha visível ou imaginária de fronteira, um Estado termina onde o outro começa. Para Scherma (2015a), a fronteira é uma porção específica de território localizada na divisa entre dois Estados e que, exatamente devido a esta característica geográfica, é um ponto onde as "relações internacionais" são mais corriqueiras.

Para Scherma (2018), o sueco Kjéllen é considerado um dos "pais" da geopolítica, ao apresentar um viés organizacionista a respeito do Estado e das fronteiras, um Estado como sendo uma espécie de "Organismo vivo", onde o Estado representa a epiderme de um corpo vivo, ou seja, é a epiderme que recebe e transmite todas as manifestações de poder emitidas e direcionadas ao "cérebro". Assim, pela analogia, tem-se presente que as fronteiras são constantemente modificadas durante a história. A fronteira como epiderme corresponderia a uma linha divisória, que separa os ambientes interno e externo. Contudo, é perceptível a existência de uma Faixa de Fronteira, ou seja, um dado espaço territorial de transição, sendo esse espaço carregado de características físicas, políticas e sociais de ambos os lados.

Por conseguinte, faz-se necessário uma leitura atenta para compreender a diferença entre "fronteira-linha" e "fronteirafaixa". Para Meira Mattos (1990, p.34), "a caracterização jurídica da fronteira é a linha de fronteira, a sua realidade cultural ou administrativa (instalação de postos de controle, alfândega, elementos de vigilância ou defesa) é a Faixa de Fronteira”. No Brasil, a legislação tem utilizado o critério de Faixa de Fronteira. Quanto ao processo de evolução do tratamento jurídico que define a extensão da Faixa de Fronteira, com início na Constituição de 1891 até a Lei nº. 6.634/79, que definiu a Faixa de Fronteira como um território de $150 \mathrm{~km}$ a partir da linha limítrofe. Essa definição foi corroborada pelo Decreto nº 85.064 de agosto de 1980, o qual é ratificado pela Constituição Federal de 1988, no parágrafo segundo do artigo 20 (Miyamoto, 1995).

A importância da fronteira não reside apenas na sua função de material, como demarcação de determinada área ou como um dispositivo destinado a impedir ou facilitar a circulação de bens e pessoas; também devido aos sentidos socialmente atribuídos na produção e difusão de imaginário territorial sobre o país. Para Durkheim (1996), a Fronteira é um fato social, é uma coisa criada (feita) pelos seres humanos. Coisa social, exterior que se impõe (coercitiva) a dada coletividade. Segundo Ferrari (2011), a ideia de fronteira vai muito além de uma linha imaginária, "é um espaço de separação de duas identidades nacionais e são igualmente um conjunto socioterritorial, produto de interações materiais e imateriais tecidas antes de tudo entre os fronteiriços" (Ferrari, 2011, p.19).

Dessa forma, as fronteiras físicas e culturais são fronteiras em movimento. As fronteiras físicas são orientadas pela lei, controladas pela polícia de fronteira, portanto as fronteiras territoriais são demarcadas por legislações (Bento, 2012). A fronteira filtra com o objetivo de proteger. Filtro esse que é moral, fundado em leis e regras preestabelecidas, tornando a fronteira, tendencialmente, um lugar de tensão.

Diante disso, os conflitos nas fronteiras brasileiras não são conflitos entre Estados, mas conflitos derivados da ausência de Estado, fronteiras sem uma maior presença do governo, oportunizando um ambiente de criminalidade, terra de ninguém que termina por ser terra ocupada pelo crime organizado (Bento, 2013; Farinha et al., 2020). Os Estados não são a principal ameaça 
à segurança e à defesa das fronteiras, mas, sim, a ausência dele, que permite a ocupação das fronteiras pela criminalidade organizada, máfias de fronteira que aproveitam-se dos espaços vazios deixados pela ausência do Estado, o que indica um processo de enfraquecimento do Estado, uma certa relação de incapacidade do governo. $\mathrm{O}$ fato é que a repercussão dessa incapacidade é percebida pelas organizações criminosas, o que poderá oportunizar um ambiente em que se possam alojar organizações, não aconselháveis na estrutura político-administrativa do Estado (Silva \& Tourinho, 2018).

Atenta-se para as fronteiras, como um ambiente em que as instituições podem separar ou integrar os Estados. A função de separação é a mais tradicional, tendo seu valor na segurança do Estado e na segurança internacional como um todo, a depender do contexto internacional. O que considera-se é que o contexto de globalização, integração regional e de avanço da atuação em rede pelas organizações criminosas, faz com que a função de integração passe a assumir maior papel na segurança do Estado e do próprio sistema internacional (Costa \& Neves, 2018). Assim, fronteira e soberania podem ser considerados conceitos que demonstram a função de integração, onde a fronteira pode assumir um espaço relevante para a defesa e segurança do Estado brasileiro.

Portanto, as Fronteiras são instrumentos institucionais de segurança pública. Se for excessivo o controle de fronteira, pode sufocar a circulação de pessoas e mercadorias, mas a ausência de controle eficaz de fronteira, deixa povos desprotegidos e o território de fronteira exposto ao crime organizado. Para Bento (2012), as fronteiras cumprem uma função social reguladora, de proteção. Aproximam e/ou separam. Podem proteger as diversidades, salvar singularidades. Enfim, fronteiras podem proteger identidades e pertenças coletivas diferentes e cultivar a integração.

\subsection{Fronteiras brasileiras: antecedentes históricos}

A formação do território brasileiro nos remete ao século XIV, início da chamada 'Era dos Descobrimentos', no momento em que as monarquias ibéricas se mostravam pioneiras nas grandes navegações. Com a descoberta do continente americano, os espanhóis adentraram em novas áreas de exploração comercial. Portugal, temendo tal ascensão marítimo-comercial, ameaçou entrar em conflito com os espanhóis. O projeto português de manutenção da colônia brasileira deu início ao processo de constituição das fronteiras brasileiras. Tal projeto tinha como objetivo a garantia do território por meio da consolidação das fronteiras. A consolidação territorial era uma forma de Portugal se afirmar no cenário europeu e afastar o desejo de conquista da Espanha sobre Portugal (Costa \& Neves, 2018).

Para Borba (2013), a evolução das fronteiras terrestres pode ser classificada em quatro fases, sendo a primeira fase a de expansão no período colonial, no qual ocorreu o deslocamento dos limites do tratado de Tordesilhas. Já a segunda fase foi caracterizada pela regularização ou legalização, no período monárquico, das ocupações territoriais para além dos limites do Tratado de Tordesilhas. A terceira fase contemplou a demarcação, no período da República, pela comissão de limites. Já a quarta fase, teve como principal objetivo o povoamento ou vivificação com a construção de fortes, instalações militares e a organização de unidades militares de fronteira (Borba, 2013).

Para Andrade (2000) e Garcia (2010), o tratado de Tordesilhas assinado em 4 de junho de 1494, que determinou a divisão das terras entre Portugal e Espanha, representou o momento em que ambos os países traçaram sua primeira fronteira oficial, uma linha reta, vertical, para terras americanas descobertas e a serem descobertas. Portanto, a linha reta vertical de Tordesilhas passou a ser a primeira referência oficial de fronteira no Brasil. Sendo assim, o Brasil já 'nasceu' com seu território delimitado.

O primeiro documento que tratou dos limites do Brasil Colônia foi o tratado de Utrecht, assinado em 1713, com a França, onde foi reconhecida a soberania de Portugal sobre as terras brasileiras. O esforço definitivo para dividir as terras das coroas de Portugal e Espanha ocorreu em 1750, com o tratado de Madri, quando Alexandre de Gusmão obteve, de fato, a legalização da expansão pelo território, desenvolvida pelos portugueses com o recurso do princípio do uti possidetis, segundo o 
qual a posse da terra é de quem a ocupou e colonizou por primeiro. Assim é que, à exceção do Acre, adquirido da Bolívia em 1903, após a ocupação de fato por seringueiros brasileiros, a configuração básica do território brasileiro é praticamente a mesma dessa época (Costa, 1991).

Portanto, o processo de construção, redefinição e consolidação das fronteiras territoriais brasileiras recebeu uma destacada contribuição do Barão de Rio Branco, em meados de 1900. Nesse período, que compreende o fim da monarquia e o início da república, procurou-se consolidar a distinção territorial nas relações do Brasil com os Estados vizinhos. À época, a fronteira territorial serviu para a afirmação, distinção e defesa da identidade nacional, através da separação territorial.

Portanto, ao longo do século, pelas derrotas e vitórias militares e diplomáticas, construiu-se e defendeu-se a atual fronteira terrestre brasileira, correspondente a $15.719 \mathrm{~km}$, com distância entre os pontos extremos de Leste-Oeste de $4.328 \mathrm{~km}$, maior que a distância norte-sul, que é de $4.320 \mathrm{Km}$. Esses números territoriais demonstram a grandiosidade do território brasileiro, se comparado aos da maioria dos Estados do mundo, ou seja, tais números revelam as responsabilidades continentais do Brasil, na gestão compartilhada de suas fronteiras.

\subsection{Arcabouços normativo constitucional e infraconstitucional}

Em 1824 a constituição do I Império, não tinha expresso a ideia de fronteira, foi somente em 1850 no II Império, que se estabeleceu a Lei de Terras, a Lei 601 que definiu a Faixa de Fronteira para efeito de concessão de terras (Borba, 2013).

As constituições brasileiras, desde 1891, demonstravam preocupação com a definição e delimitação de áreas especiais à defesa nacional, mas de fato, somente com a constituição de 1934, a expressão "Faixa de Fronteira" passou a ser utilizada. Assim, desde o início da delimitação territorial, as fronteiras mantiveram-se como foco primordial de política de segurança nacional. Cabe destacar que a Lei 601 considerava a fronteira como uma área de segurança nacional e estabeleceu uma faixa de dez léguas ao longo de todo o território nacional.

Segundo Borba (2013), ao longo do período de 1824-1988 a evolução da Legislação brasileira que versa ou faz referência à Fronteira e ou Faixa de Fronteiras estão assim, cronologicamente organizadas:

- 1824 (Império): Constituição Política do Império de Brasil. Largura da Faixa de Fronteira: 66 km (10 léguas), referenciada na Lei $n^{\circ} 601$.

- 1891 (República): Constituição dos Estados Unidos do Brasil. Em seu artigo 64 fazia menção a fronteira e não definia largura da Faixa de Fronteira.

- 1927 Decreto n ${ }^{\circ} 17.999$ criou o CDN - Conselho de Defesa Nacional

- 1934 (República): Constituição dos Estados Unidos do Brasil. Em seu artigo 166 fazia menção a fronteira sendo definida a largura da Faixa de Fronteira: $100 \mathrm{Km}$.

- 1937 (República): Constituição dos Estados Unidos do Brasil. Em seu artigo 165 fazia menção a fronteira sendo definida a largura da Faixa de Fronteira: $150 \mathrm{Km}$.

- 1939 Decreto-Lei n ${ }^{\circ}$ 1.164 Dispõe sobre as concessões de terras e vias de comunicação na faixa da fronteira, bem como sobre as indústrias aí situadas.

- 1946 (República): Constituição dos Estados Unidos do Brasil. Em seus artigos 176 e 180 fazia menção a fronteira sendo definida a largura da Faixa de Fronteira: $150 \mathrm{Km}$.

- 1946 Decreto-Lei no 9.760 Dispõe sobre bens imóveis da União

- 1955 Lei n 2.597 Dispõe sobre zonas indispensáveis à defesa do país e dá outras providências. Revogada pela Lei no 6.634 de 1979.

- 1964 Lei no 4.504 Estatuto da Terra.

- 1966 Lei no 4.947 Fixa normas de Direito Agrário. 
- 1967 (República): Constituição da República Federativa do Brasil. Em seu artigo 89 fazia menção a fronteira sendo definida a largura da Faixa de Fronteira: $150 \mathrm{Km}$.

- 1970 Decreto-Lei no 1.094 Dispõe sobre a Comissão Especial da Faixa de Fronteira e dá outras providências.

- 1970 Decreto-Lei no 1.135 Dispõe sobre a organização, competência e funcionamento do Conselho de Segurança Nacional.

- 1971 Lei nº 1.164 Dispõe sobre terras públicas.

- 1975 Decreto-Lei no 1.414 Dispõe sobre terras devolutas em "Faixa de Fronteiras".

- 1976 Decreto-Lei ${ }^{\circ} 1.455$ Dispõe sobre bagagem de passageiro procedente do exterior, estabelece normas sobre mercadorias estrangeiras apreendidas e dá outras providências.

- 1978 Lei no 6.559 Extingue a Comissão Especial da Faixa de Fronteira e dá outras providências.

- 1979 Lei n $^{\circ} 6.634$ Dispõe sobre a Faixa de Fronteira, altera o Decreto-Lei no 1.135 de 1970. A Lei no 6.634 foi alterada pela Lei $\mathrm{n}^{\circ} 13.097$ de 19 de janeiro de 2015.

- 1979 Lei no 6.739 Matrícula e Registro de Imóveis Rurais.

- 1980 Decreto no $^{\circ} 5.064$ regulamenta a Lei no 6.634 de maio de 1979, que dispõe sobre a Faixa de Fronteira.

- 1987 Decreto-Lei n 2.375 Revoga a Lei no 1.164 que dispõe sobre terras públicas.

- 1988 Decreto 96.084 Regulamenta o $§ 1^{\circ}$ do art. $5^{\circ}$ do Decreto-Lei ${ }^{\circ} 2.375$ de 1987, que autoriza a União a transferir, a título gratuito, a Estados ou Territórios, terras públicas a ela pertencentes, localizadas na Faixa de Fronteira.

- 1988 (República): Constituição da República Federativa do Brasil, em seus artigos 20,91,144 e 176 faz menção e ou referência a fronteira, permanecendo a largura da Faixa de Fronteira de 150 km vigente.

Para dar prosseguimento a organização cronológica da legislação brasileira que versa ou faz referência à Fronteira e ou Faixa de Fronteiras posterior a 1988, utilizou-se de uma pesquisa exploratória na base normativa do Centro de Documentação e Informação (Cedi) da Câmara dos Deputados juntamente com a base LexML - Rede de Informação Legislativa e Jurídica. Após pesquisas nas Bases já nominadas, segue-se a evolução da Legislação brasileira que versa ou faz referência à Fronteira e ou Faixa de Fronteiras estão assim, cronologicamente organizada:

- 1991 Lei no 8.183 Dispõe sobre a organização e funcionamento do Conselho de Defesa Nacional e dá outras providências.

- 1999 Lei n 9.871 Estabelece prazo para as ratificações de concessões e alienações de terras feitas pelos Estados na "Faixa de Fronteira".

- 1999 Decreto no 3.026 Promulga o Convênio para a Preservação, Conservação e Fiscalização dos recursos naturais nas áreas de Fronteira, celebrado entre o Governo da República Federativa do Brasil e o Governo da República da Bolívia.

- 1999 Lei Complementar nº 97 Dispõe sobre as normas gerais para organização, o preparo e o emprego das Forças Armadas.

- 2000 Decreto n 3.467 Promulga o acordo entre a República Federativa do Brasil e a República Argentina para o funcionamento do "Centro Único de Fronteira" São Borja - Santo Tomé.

- 2001 Lei no 10.363 Prorroga o prazo para as ratificações de concessões e alienações de terras feitas pelos Estados na "Faixa de Fronteira".

- 2009 Lei n ${ }^{\circ} 11.952$ Dispõe sobre a regularização fundiária das ocupações incidentes em terras situadas em áreas da União.

- 2010 Decreto sem número de 8 de setembro. Institui a Comissão Permanente para o Desenvolvimento e a Integração da Faixa de Fronteira - CDIF.

- 2011 Decreto 7.496 Institui o Plano Estratégico de Fronteiras PEF. 
- 2012 Lei n $^{\circ} 12.723$ Disciplina o regime de entreposto aduaneiro, estabelece normas sobre mercadorias estrangeiras apreendidas e dá outras providências, para autorizar a instalação de lojas francas em Municípios da Faixa de Fronteira cujas sedes se caracterizam como cidades gêmeas.

- 2016 Decreto no 8.903 Institui o Programa de Proteção Integrada de Fronteiras PPIF e organiza a atuação de unidades da administração pública federal para sua execução. Revogou o Decreto 7.496 Institui o Plano Estratégico de Fronteiras PEF.

- 2019 Decreto ${ }^{\circ} 9.818$ de 3 de junho do ano corrente, altera o Decreto $\mathrm{n}^{\circ}$ 8.903, de 16 de novembro de 2016, que institui o Programa de Proteção Integrada de Fronteiras e organiza a atuação de unidades da administração pública federal para sua execução.

- 2019 Decreto n 9.961 Institui a Comissão Permanente para o Desenvolvimento e a Integração da Faixa de Fronteira, revogando o Decreto sem número de 8 de setembro de 2010 que instituiu a Comissão Permanente para o Desenvolvimento e a Integração da Faixa de Fronteira - CDIF.

Ao observar a evolução constitucional, normativa e legal da Faixa de Fronteira brasileira, que variou ao longo da história, de $66 \mathrm{~km}$ (dez léguas), $100 \mathrm{~km}$ e $150 \mathrm{~km}$, verifica-se que sempre houve uma estrutura do governo atuante nas áreas de fronteira, voltada para a presença militar, a colonização e concessões.

A regulamentação do uso da Faixa de Fronteira como definida na Lei 6.634 de 1979 e regulada pelo Decreto 85.064 de 1980, tem como órgão executor o Conselho de Defesa Nacional. A Constituição de 1988 determina por meio de legislação ordinária a regulamentação de usos das faixas de fronteira, mas é a União que mantém em vigilância a Lei 6.634/1979, fixando atribuições de controles prévios ao Conselho de Defesa Nacional, em locais indispensáveis à segurança nacional (BORBA, 2013).

\subsection{Programas e ações de segurança e defesa nacional na faixa de fronteira e suas repercussões}

A Constituição Federal define que a "segurança pública, é dever do Estado, direito e responsabilidade de todos, é exercida para a preservação da ordem pública e da incolumidade das pessoas e do patrimônio" (Art. 144). Os órgãos responsáveis pela segurança pública são: a Polícia Federal, a Polícia Rodoviária Federal, a Polícia Ferroviária Federal, as Polícias Civis, as Polícias Militares e os Corpos de Bombeiros Militares (Art. 144).

Na política internacional, o conceito de segurança aparece tradicionalmente associado à segurança dos Estados. Daí o uso recorrente do termo "segurança nacional", associada à defesa do Estado, à capacidade militar e à guerra. Segurança e defesa nacionais são conceitos complementares. Apesar de muitas vezes utilizarem os dois termos de forma intercambiável, podemos identificar algumas distinções nos significados atribuídos a cada um dos termos (Rego Monteiro, 2014).

Uma primeira diferenciação é a que relaciona segurança ao âmbito interno e defesa ao âmbito externo. Outra explicação é a que dá o nome de defesa àquilo que os militares fazem, enquanto segurança, é de responsabilidade de múltiplas agências, incluindo os militares. No mesmo sentido, a defesa pode ser associada aos conflitos entre Estados, enquanto segurança incluiria um espectro mais amplo de conflitos domésticos, transnacionais e não estatais (Rego Monteiro, 2014).

A Política de Defesa Nacional (PDN), decreto presidencial no 5.484 de 30 de junho de 2005 definem segurança e defesa: segurança "é a condição em que o Estado, a sociedade ou os indivíduos não se sentem expostos a riscos ou ameaças, enquanto defesa é a ação efetiva para se obter ou manter o grau de segurança desejado" (Bento, 2013).

Para Andrade e Lima (2018), no âmbito dos marcos regulatórios, as legislações de relevância referentes à temática das fronteiras são a Lei no 6.634 de 1979 e a Constituição Federal de 1988. Ambas consideram a Faixa de Fronteira área essencial à segurança nacional, com até $150 \mathrm{~km}$ de largura ao longo das fronteiras terrestres, com pontos de interesse estratégico do Estado e que merecem relevante atenção nessas regiões. Ainda é importante ressaltar que há diversas legislações adicionais, muitas delas tratando de questões fundiárias, infraestrutura e desenvolvimento regional. 
Essas legislações foram acompanhadas de novos programas e ações que surgiram para a área, principalmente em fins das décadas de 1990 e 2000. Vale ressaltar que até a década de 2000, as políticas públicas orientadas a essa região mantiveram o tradicional enfoque de segurança e defesa. Tal posicionamento foi gradualmente sendo alterado em virtude das novas condições da política externa brasileira e da integração regional, resultando em um novo enfoque com ênfase no desenvolvimento regional.

No ano de 1999, o Programa de Desenvolvimento Social da Faixa de Fronteira (PDSFF), foi um grande marco, pois pela primeira vez, a região recebia uma política com viés regional, foi o primeiro programa cuja principal vertente não era militar e abrangia toda a Faixa de Fronteira brasileira (Scherma, 2015b).

Ainda que inédito, o programa passou por diversas dificuldades que o impediram de atingir em sua totalidade seu objetivo central. Muito embora pudesse ser considerado um marco nas concepções de políticas de fronteira do Brasil, ele ainda apresentava fragilidades, como a não diferenciação entre sub-regiões de fronteira, o seu funcionamento apenas sob demanda de parlamentares, a ausência de mecanismos de participação formal da sociedade e as dificuldades técnicas nos municípios executores (Scherma, 2015b).

Estudos realizados pelo Ministério de Integração de 2003 a 2005, o programa seria reorganizado e renomeado como Programa de Promoção do Desenvolvimento da Faixa de Fronteira (PDFF). Inicialmente o objetivo era reorganizar, centralizar e reestruturar as ações para a região de fronteira do país, visando à formação de uma agenda positiva voltada para o desenvolvimento em bases integradas e sustentáveis (Scherma, 2015b).

Posteriormente ao fim do PDFF em 2010, foi criada a Comissão Permanente para o Desenvolvimento e Integração da Faixa de Fronteira (CDIF) com o objetivo de dar continuidade às políticas de desenvolvimento regional originadas no PDFF, e dar por encerrado o referido programa. A CDIF visa se consolidar como instituição central da formulação e coordenação das políticas para a Faixa de Fronteira (Neves, Silva \& Monteiro, 2016).

Desta forma, por meio de pesquisa documental foi realizado um mapeamento dos programas e ações de segurança e defesa nacional na Faixa de Fronteira brasileira conforme o Quadro 1 a seguir.

Quadro 1 - Programa e Ações de Segurança e Defesa para Fronteira Brasileira.

\begin{tabular}{|l|l|c|l|l|l|}
\hline \multicolumn{5}{|c|}{ FRONTEIRA BRASILEIRA - PRINCIPAIS POLÍTICAS FEDERAIS } \\
\hline \multicolumn{1}{|c|}{ Ministério } & \multicolumn{1}{|c|}{ Política } & Ano & \multicolumn{1}{|c|}{ Objetivo } & Abrangência & \multicolumn{1}{c|}{ Prioridade } \\
\hline $\begin{array}{l}\text { Órgão de } \\
\text { Inteligência, } \\
\text { Receita Federal, } \\
\text { Forças Armadas }\end{array}$ & $\begin{array}{l}\text { Programa de } \\
\text { Proteção } \\
\text { Integrada de } \\
\text { Fronteira (PPIF) }\end{array}$ & $\mathbf{2 0 1 6}$ & $\begin{array}{l}\text { Promover uma atuação } \\
\text { integrada e coordenada } \\
\text { de órgãos de segurança } \\
\text { pública, envolvendo } \\
\text { também autoridades de } \\
\text { municípios fronteiriços e } \\
\text { de países vizinhos. }\end{array}$ & $\begin{array}{l}\text { Faixa de } \\
\text { Fronteira }\end{array}$ & $\begin{array}{l}\text { Fortalecimento das ações } \\
\text { de preservação, controle e } \\
\text { repressão de delitos } \\
\text { transfronteiriços. }\end{array}$ \\
\hline $\begin{array}{l}\text { Defesa, Justiça e } \\
\text { Cidadania e } \\
\text { Relações } \\
\text { Exteriores }\end{array}$ & $\begin{array}{l}\text { Comitê de } \\
\text { coordenação e } \\
\text { controle de } \\
\text { fronteiras }\end{array}$ & $\mathbf{2 0 1 6}$ & $\begin{array}{l}\text { Integrar as políticas e } \\
\text { mecanismos de combate } \\
\text { a ilícitos }\end{array}$ & $\begin{array}{l}\text { Faixa de } \\
\text { Fronteira }\end{array}$ & $\begin{array}{l}\text { Contrabando de produtos } \\
\text { armas, tráfico de drogas } \\
\text { ilegais e crimes de } \\
\text { descaminho }\end{array}$ \\
\hline $\begin{array}{l}\text { Forças Armadas } \\
+ \text { instituições } \\
\text { federais + estados } \\
+ \text { municípios }\end{array}$ & $\begin{array}{l}\text { Operação Ágata } \\
11\end{array}$ & $\mathbf{2 0 1 6}$ & $\begin{array}{l}\text { Reduzir os índices de } \\
\text { criminalidade e reprimir } \\
\text { crimes transfronteiriços, } \\
\text { como o tráfico de } \\
\text { pessoas, drogas, armas e } \\
\text { munições e o } \\
\text { contrabando de } \\
\text { mercadorias, e } \\
\text { ambientais. }\end{array}$ & $\begin{array}{l}\text { Principais pontos } \\
\text { de fronteira do } \\
\text { país }\end{array}$ & $\begin{array}{l}\text { Combate a crimes } \\
\text { transfronteiriços e } \\
\text { ambientais }\end{array}$ \\
\hline
\end{tabular}




\begin{tabular}{|c|c|c|c|c|c|}
\hline Fazenda (RFB) & $\begin{array}{l}\text { Operação } \\
\text { Muralha }\end{array}$ & 2016 & $\begin{array}{l}\text { Reduzir os índices de } \\
\text { contrabando e } \\
\text { descaminho }\end{array}$ & $\begin{array}{l}\text { Principais pontos } \\
\text { de fronteira do } \\
\text { país }\end{array}$ & $\begin{array}{l}\text { Combate a crimes } \\
\text { tributários e fiscais }\end{array}$ \\
\hline $\begin{array}{l}\text { Justiça e } \\
\text { Cidadania, } \\
\text { Defesa e Fazenda }\end{array}$ & $\begin{array}{l}\text { Plano } \\
\text { Estratégico de } \\
\text { Fronteiras } \\
(\text { PEF) }\end{array}$ & 2011 & $\begin{array}{l}\text { Aperfeiçoar a gestão } \\
\text { integrada das instituições } \\
\text { envolvidas com } \\
\text { segurança pública nas } \\
\text { regiões de fronteira }\end{array}$ & $\begin{array}{l}\text { Municípios da } \\
\text { Faixa de } \\
\text { Fronteira }\end{array}$ & Segurança e comércio \\
\hline $\begin{array}{l}\text { Justiça e } \\
\text { Cidadania, } \\
\text { Defesa e Fazenda }\end{array}$ & $\begin{array}{l}\text { Estratégia } \\
\text { Nacional de } \\
\text { Segurança } \\
\text { Pública nas } \\
\text { Fronteiras } \\
\text { (Enafron) } \\
\text { Coordenaçã } \\
\text { o Senasp } \\
\end{array}$ & 2011 & $\begin{array}{l}\text { Estratégia de Defesa e } \\
\text { controle da aduana }\end{array}$ & $\begin{array}{l}\text { Municípios da } \\
\text { Faixa de } \\
\text { Fronteira. } \\
\text { Fortalecimento } \\
\text { de instituições } \\
\text { estaduais e } \\
\text { municipais, etc. }\end{array}$ & Segurança e comércio \\
\hline $\begin{array}{l}\text { Justiça e } \\
\text { Cidadania (PF, } \\
\text { PRF e Senasp) } \\
\end{array}$ & $\begin{array}{l}\text { Operação } \\
\text { Sentinela }\end{array}$ & 2010 & $\begin{array}{l}\text { Enfrentar os crimes de } \\
\text { fronteira, entre eles o } \\
\text { tráfico de drogas }\end{array}$ & $\begin{array}{l}\text { Principais pontos } \\
\text { de fronteira do } \\
\text { país }\end{array}$ & $\begin{array}{l}\text { Segurança e tráfico de } \\
\text { drogas }\end{array}$ \\
\hline $\begin{array}{l}\text { Integração } \\
\text { Nacional }\end{array}$ & $\begin{array}{l}\text { Plano de } \\
\text { Desenvolviment } \\
\text { o da Faixa de } \\
\text { Fronteira } \\
\text { (PDFF) }\end{array}$ & 2009 & $\begin{array}{l}\text { Promover o } \\
\text { desenvolvimento da FF, } \\
\text { com ênfase nas } \\
\text { potencialidades locais e } \\
\text { na articulação com } \\
\text { outros países da América } \\
\text { do Sul }\end{array}$ & $\begin{array}{l}\text { Municípios da } \\
\text { Faixa de } \\
\text { Fronteira }\end{array}$ & $\begin{array}{l}\text { Estruturação física, social } \\
\text { produtiva }\end{array}$ \\
\hline Defesa (Exército) & $\begin{array}{l}\text { Programa } \\
\text { Amazônia } \\
\text { protegida }\end{array}$ & 2008 & $\begin{array}{l}\text { Aumentar o número de } \\
\text { pelotões de fronteira na } \\
\text { floresta e modernizá-los, } \\
\text { além de criar novas } \\
\text { brigadas }\end{array}$ & $\begin{array}{l}\text { Municípios da } \\
\text { Faixa de } \\
\text { Fronteira }\end{array}$ & Segurança e social \\
\hline Defesa & $\begin{array}{l}\text { Programa Calha } \\
\text { Norte }\end{array}$ & 1985 & $\begin{array}{l}\text { Promover a ocupação e o } \\
\text { desenvolvimento da } \\
\text { Amazônia }\end{array}$ & $\begin{array}{l}6 \text { estados (194 } \\
\text { municípios) }\end{array}$ & $\begin{array}{l}\text { Segurança, } \\
\text { desenvolvimento, } \\
\text { econômico, social e } \\
\text { ambiental }\end{array}$ \\
\hline
\end{tabular}

Portanto, a legislação brasileira buscou beneficiar, por mecanismo de compensação, as faixas de fronteira. Atualmente, novas estratégias tecnológicas e econômicas, muito mais complexas, estão sendo formuladas, é evidente a necessidade de reavaliar o significado das faixas de fronteira, mantida pela força da inércia do passado, uma vez que as fronteiras estão sendo diluídas pela força da globalização.

Para Andrade e Lima (2018), nota-se a emergência de uma perspectiva de interagência para o trato da questão da fronteira. No entanto, é importante ressaltar que os marcos regulatórios não tratam diretamente das questões de segurança e defesa. Desta forma, é necessário também analisar as políticas de defesa do país, bem como, as ações militares e de segurança na Faixa de Fronteira.

\subsection{As iniciativas e ações de segurança e defesa nas fronteiras do brasil}

Com base nos conceitos e concepções brasileiras sobre segurança e defesa das fronteiras, faz-se necessário abordar as principais iniciativas e ações e suas repercussões nas áreas das fronteiras brasileiras. No contexto das iniciativas e ações, cabe destacar que anteriormente à criação do MD, da PDN e da END, já havia iniciativas com ênfase na proteção da Faixa de Fronteira, o programa calha norte (PCN) criado em 1985, logo após o projeto de vigilância da Amazônia/Sistema de proteção da Amazônia 
(Sivam/Sipam), o Sistema de monitoramento das Fronteiras, o Plano Estratégico de Fronteiras (PEF) e o Plano de Proteção Integrado das Fronteiras (PPIF) (Nunes, 2017; Andrade \& Lima, 2018).

Para Andrade e Lima (2018), embora haja problemas de articulação e implementação de muitos desses projetos, as ações de segurança e defesa das fronteiras têm se expandido em termos de concepção de mera defesa territorial com foco na Amazônia para uma proteção mais ampla na Faixa de Fronteira. Portanto, o foco na dimensão militar destona para um foco mais no âmbito interagências.

No período de redemocratização, o principal projeto para a defesa das fronteiras foi o PCN. No que se refere à Faixa de Fronteira, o PCN considerou a região escassamente povoada. Ainda que fosse apresentado como um programa de cunho civilmilitar e com uma abordagem mais abrangente na proteção da Região Amazônica e das fronteiras, inicialmente, o PC apenas ofereceu resultados para demandas de cunho militar. Do total de recursos orçamentários destinados ao projeto, $46 \%$ foram para o Ministério do Exército; 21,4\% para o Ministério da Marinha; 18,9\% para a FUNAI; 10,5\% para o Ministério da Aeronáutica; e 3,2\% para outros. O programa também sofreu críticas por seu processo de formulação e implementação ocorrer preponderantemente em meios do governo, com pouca participação da sociedade e da população local (Andrade \& Lima, 2018; Myamoto, 2009; Scherma, 2016; Rocha 2019).

O programa em 2004 começou a retomar sua importância, principalmente em sua vertente civil, pois a ala civil de desenvolvimento regional passou a receber mais recursos do que a militar. Atualmente o programa atinge cerca de 380 municípios em oito estados da federação. No tocante à proteção das fronteiras, outra iniciativa merece destaque: O Sivam/Sipam, um sistema de Vigilância e Monitoramento com o intuito de proteger as fronteiras norte e Região Amazônica.

Posteriormente ao Sivam/Sipam, a dimensão de segurança nas políticas de fronteira brasileiras perdeu importância na agenda nacional durante o início dos anos 2000. Para Scherma (2016), a proteção das fronteiras continuou de forma tímida na agenda de defesa do Brasil, todavia o PDSFF, o PDFF e a CDIF denotaram a ampliação de questões relativas ao desenvolvimento regional e, principalmente a mobilização e integração dos vários atores federativos nessas áreas, fato esse considerado um avanço significativo no olhar da fronteira não apenas com um viés de segurança e defesa nacional. No entanto, o surgimento de novas iniciativas à proteção da Faixa de Fronteira só ocorreu após a publicação da END, em 2008 (Andrade \& Lima, 2018).

Assim, em 2011 após a END duas significativas iniciativas orientadas para postura contemporânea de proteção das fronteiras do Brasil foram anunciadas, a primeira iniciativa foi o Plano Estratégico de Fronteira (PEF) que contempla ainda a Estratégia Nacional de Segurança Pública nas Fronteiras (ENAFRON) e a segunda iniciativa foi o Sistema Integrado de Monitoramento de Fronteiras (SISFRON). O Decreto no 7.496/2011 instituiu o PEF com o objetivo de fortalecer a prevenção, controle, fiscalização e repressão dos delitos transfronteiriços e dos delitos praticados na Faixa de Fronteira brasileira. (Filho \& Ruckert, 2015).

O PEF prevê a atuação conjunta do Brasil como os países limítrofes por meio da realização de parcerias para a atuação nas ações e de ações cooperação internacional como os países vizinhos. O PEF é baseado em dois eixos de atuação: a chamada Operação Sentinela e a Operação Ágata. A Operação Sentinela, é de caráter permanente e com foco em ações de inteligência, sendo estas intensificadas, passando a contar com o apoio das Forças Armadas. Já a Operação Ágata é de natureza pontual e temporária, com caráter repressivo e também com participação das Forças Armadas. (Brasil, 2012).

A partir dos primeiros resultados do PEF, foi lançado a ENAFRON como uma proposta complementar com o intuito de promover a articulação dos atores governamentais das três esferas de governo no sentido de fomentar políticas públicas de segurança, uniformizar entendimentos e ações e otimizar o investimento de recursos públicos nas regiões de fronteira. Assim, através da ENAFRON o governo brasileiro promove a presença permanente de instituições policiais e de fiscalização na fronteira através de ações integradas de diversos órgãos federais, estaduais e municipais para prevenir e reprimir ilícitos transnacionais. 
Cabe ressaltar ainda que no âmbito do Projeto Policiamento Especializado de Fronteira (PEFRON), foi uma das ações, mais efetivas em relação à segurança das fronteiras (Brasil, 2012).

Além do PEF a segunda iniciativa, o SISFRON que constitui-se de um conjunto de ações para a defesa das fronteiras coordenado pelo Exército Brasileiro e em consonância com os princípios de monitoramento/controle, mobilidade e presença da END, o programa é descrito como um "sistema de comando e controle, comunicações, computação, inteligência, vigilância e reconhecimento que visa dotar a Força Terrestre de meios habilitadores a uma presença efetiva na Faixa de Fronteira brasileira", e seu principal objetivo é fortalecer a defesa territorial e garantir a soberania nacional na Faixa de Fronteira, contribuindo decisivamente com o esforço de desenvolver e manter efetivo controle dessas áreas (Brasil, 2012; Scherma, 2016; Neves, Silva \& Monteiro, 2016, Resende, 2018).

Ainda em relação ao SISFRON, é um programa complexo, contendo várias etapas, com diversas demandas tecnológicas e operacionais, incorrendo em altos custos, com investimentos estimados inicialmente em $\mathrm{R} \$ 11.992$ bilhões tendo como objetivo sua implantação gradual com o início em 2011 e término em 2035, portanto sendo uma iniciativa ambiciosa e cara (Andrade \& Lima, 2018).

Cabe destacar, todavia, que os méritos das novas propostas de enfrentamento dos desafios de defesa e segurança nas fronteiras, desde meados de 2011, não as isenta de dificuldades de implementação e gestão dos projetos. Tanto é fato, que em 2015 foi publicado um relatório de auditoria do Tribunal de Contas da União (TCU) no qual são elencadas falhas, como a não adoção de elementos básicos de atuação conjunta com critério de priorização, complementaridade e coordenação de ações e diretrizes de integração e acompanhamento. Na visão do TCU, um dos problemas centrais das iniciativas é a ausência de uma Política Nacional de Fronteira capaz de definir atribuições e coordenar as atividades de todos os órgãos criados para atuar na Faixa de Fronteira (Brasil, 2015; Andrade \& Lima, 2018).

O Programa de Proteção Integrada de Fronteiras (PPIF), tem por antecessor o Plano Estratégico de Fronteiras (PEF), instituído pelo Decreto n $\mathrm{n}^{\circ}$ 7.496/2011 instrumento normativo adotado dentro de um conjunto de políticas públicas que tinha por objetivo o fortalecimento da faixa de fronteira, diante da ameaça produzida pela ação do crime organizado transnacional, em especial da produção e tráfico de drogas e de ilícitos conexos e da consequente necessidade de se fortalecer a presença governamental naquela porção sensível do território nacional (Brasil, 2015).

Portanto o PPIF passa a ser uma atualização do antigo PEF e tem como intuito de elevar a articulação entre os ministérios e os demais órgãos da administração pública relacionados à segurança e defesa das fronteiras e organizar a atuação da administração pública para sua execução. Essa nova política para as fronteiras é uma resposta ao relatório do TCU que observou a necessidade de uma governança centralizada para o aperfeiçoamento da atuação nas questões fronteiriças. Segundo TCU, concluiu-se que as políticas adotadas deveriam permitir a implementação de ações operacionais sistêmicas e permanentes, incluindo as essenciais atividades de inteligência, e envolver a cooperação internacional (Brasil, 2015).

Muito do que está presente na PPIF estava concebido também na PEF, entretanto a PPIF busca aprofundar a integração das instituições, começando por uma maior integração no alto nível, criando assim uma instância de alto nível para articular-se com os níveis estaduais e municipais. Desse modo, espera-se aumentar o potencial político de implementação das políticas voltadas para a fronteira. Além disso, a cooperação com os países vizinhos também já preconizada no PEF, ganha corpo com a inclusão do MRE, da Abin e da CDIF nessa nova política de fronteira. Por fim, cabe ressaltar que as críticas realizadas pelo relatório do TCU não foram plenamente atendidas, criando uma expectativa de que mecanismos futuros sejam criados para sanálas e dar continuidade às iniciativas brasileiras nas regiões de fronteiras (Costa, 2017).

Portanto, todas essas iniciativas, ações, projetos e programas aliados a uma nova visão quer reforçar a importância de políticas públicas com ênfase no desenvolvimento regional das faixas de fronteiras, denotam um avanço e uma maior atenção para com essas áreas. Segundo Andrade e Lima (2018), há a expansão da demanda de equalizar uma visão de desenvolvimento 
e de segurança em detrimento de uma visão de apenas defesa do território. Nota-se que também há um aumento de políticas públicas que focam na segurança das fronteiras terrestres e na demanda de atuação interagências e da cooperação com os países vizinhos, na busca conjunta de garantir a segurança nacional e também o desenvolvimento socioeconômico dessas áreas.

\section{Considerações Finais}

A pesquisa identifica as fronteiras brasileiras algo complexo, emblemático, pela sua enorme extensão, pelo seu um elevado nível de interação, a relevante conexão de seus problemas de segurança pública, com as dinâmicas transfronteiriças. Face a importância estratégica e geopolítica, a Faixa de Fronteira passa a ser uma área de preocupação, de extrema pertinência para a segurança e defesa nacional, uma vez que, delimita territórios sob autoridade estatal (soberania), bem como se configura em um local de grande fluxo de bens, serviços e pessoas.

A Faixa de Fronteira é uma região que historicamente é vista com viés da defesa e da segurança, motivo pelo qual a maior parte das políticas públicas para as fronteiras tem como base ações das polícias e Forças Armadas.

No Brasil essa situação se arrasta desde a delimitação territorial, ao ser vista como região onde a prioridade das políticas é a defesa e segurança, isso de certa forma, corrobora para o atraso do desenvolvimento dessas regiões em relação às demais regiões do país. Todavia, o atraso contribuiu para o crescimento das redes ilegais do narcotráfico e armas, aumentando também os índices de violência e criminalidade, que por sua vez, requer políticas mais repressivas.

Portanto, ao longo dos últimos anos, as políticas de proteção da Faixa de Fronteira brasileira vêm sofrendo alterações. Alguns dos processos que contribuíram para essas alterações foram, o fim da Guerra Fria, a redemocratização, a reaproximação com a Argentina e os avanços da integração regional na América do Sul, bem como os novos marcos legais baseados no desenvolvimento regional e sustentabilidade.

Em meio a essa nova conjuntura, lentamente somam-se as políticas de defesa e segurança, ações, projetos e programas que visam o desenvolvimento socioeconômico e de cooperação com os países vizinhos, com o intuito de colaborar para amenizar os problemas da Faixa de Fronteira. Observa-se aí um esforço em desenvolver políticas públicas, leis específicas, orientadas também ao desenvolvimento regional e a melhoria da capacidade das Forças Armadas e dos órgãos de segurança pública nas regiões de fronteira, representando um avanço na capacidade de atuação por parte do Estado.

O ponto culminante desse esforço dá-se no governo Lula da Silva, especialmente com a criação do PDFF, concebido como alavanca para o desenvolvimento local. Desta forma, o governo conseguiu manter as políticas de defesa e segurança e acrescentar o viés do desenvolvimento regional, introduzindo o PND e a END, que incorporam a questão de cooperação entre os vizinhos, tanto em ações relativas à defesa e segurança nas fronteiras como ações conjuntas que visem o desenvolvimento socioeconômico dessas áreas.

Assim, fica evidente que há um aumento da demanda de cooperação e participação de atores, seja no âmbito local, com as polícias, Abin, Ibama etc., seja no âmbito internacional, com propostas de ampliação da cooperação com os países vizinhos. Do PCN ao PPIF e o Sisfron, tem havido um considerável aumento das regiões nas quais esses atores buscam atuar e cooperar.

Contudo, vemos um movimento onde as ações, políticas e os projetos para o desenvolvimento têm perdido espaço em função de uma nova valorização das políticas de defesa e segurança por parte do atual governo, o que indica um enfraquecimento da visão de desenvolvimento regional e cooperação. Mesmo assim, algumas políticas focadas na promoção do desenvolvimento por meio da cooperação continuam existindo, mas de forma menos institucionalizada e sofrendo com os constantes contingenciamentos de recursos.

De forma geral, é possível afirmar que as políticas governamentais para as fronteiras do Brasil se caracterizam por serem desarticuladas, com sérias dificuldades de continuidade e também por terem pouca participação da população no processo de formação das mesmas. No que se refere à descontinuidade, observa-se que as ações, programas, projetos e políticas 
direcionais, em relação às fronteiras, ao longo do tempo vêm passando por alterações de nomes, fusões, e divisões evidenciando a desorganização e falta de articulação, o que explica a pouca eficácia de tais ações. Por vezes fica evidente que as políticas oficiais para fronteira atendem os interesses de grandes grupos de poder que se utilizam de um discurso de integração e credibilidade discutível.

Com base nos documentos oficiais e o arcabouço legal, percebe-se dificuldades de integração e políticas conjuntas, uma vez que, se esbarram nas legislações diferentes que versam sobre temas específicos entre os países, desta forma, inibindo implementações de vetores de cooperação e integração com os vizinhos de um modo geral. A partir do presente trabalho, é notório que mesmo reconhecendo os enlaces entre desafios de segurança e interação com o desenvolvimento nos espaços fronteiriços, tal fato aponta para a necessidade de melhor compreensão das peculiaridades das dinâmicas locais para um efetivo resultado das políticas, seja de cunho securitário ou de desenvolvimento para essas regiões.

Percebe-se ainda, a necessidade de constantes atualizações nas legislações que tratam das regiões de fronteiras e em especial da Faixa de Fronteira para minimizar os obstáculos que reduzem a capacidade de inserção dos Estados nos circuitos econômicos nacional, regional e internacional. Surge nesse contexto um novo conceito de fronteira, que requer uma maior atuação do Estado como indutor de atividades econômicas geradoras de emprego e renda para essas regiões.

Ainda que o Brasil tenha avançado em suas concepções, para tratar dos problemas de segurança, os programas em andamento demonstram resultados pouco satisfatórios, para atingir os objetivos propostos por PND, END e Enafron. O que indica a necessidade de constantes revisões acerca da continuidade dos programas iniciados, sempre com visão de Estado e perspectiva de médio e longo prazo.

Portanto, a Faixa de Fronteira é assim entendida, como uma área legalmente estabelecida pelo Estado, para direcionar um tratamento político diferenciado em relação ao restante das demais regiões do Brasil. Essa faixa, por se tratar de um espaço de atuação organizacional, está sujeita aos efeitos dos padrões de comportamento das organizações. Até o momento, preponderam comportamentos organizacionais baseados em critérios de defesa nacional, a concepção da faixa de fronteira tem se mantido predominantemente nesse sentido.

Por fim, em futuros estudos, pretende-se compreender como são formuladas as políticas públicas locais nos espaços fronteiriços para, posteriormente, determinar o impacto dessas políticas nos cenários de cooperação e integração internacional no contexto do Desenvolvimento Regional.

\section{Referências}

Anderson, B. (1989). Nação e consciência nacional. Editora Ática.

Andrade, M. C. (2000). A trajetória do Brasil (1500 a 2000). Contexto.

Andrade, I. de O. \& Lima, R. C.(2018). Segurança e Defesa Nacional nas Fronteiras Brasileiras. In Bolívar Pêgo (Org.), et al. Fronteiras do Brasil: uma avaliação de política pública. 1, (111-150).

Beaulac, S. (2003). The Social Power of Bodin's 'Sovereignty' and International Law. Melbourne Journal of International Law. The University of Melbourne. Faculty of Law.

Bento, F. R. (2012). Fronteira, significado e valor - A partir do estudo da experiência das cidades-gêmeas de Rivera e Santana do Livramento. In: Bento, F. R. (Org.) Fronteiras em Movimento. (13-30). Paco Editorial.

Bento, F. R. (2013). Cidades de Fronteira e Integração Sul-Americana. Paco Editorial.

Bhabha, H. K. (2001). O Local da Cultura. Editora UFMG.

Bodin, J. (1992). On Sovereignty. Series: Cambridge Texts in the History of Political Thought Jean Bodin. Ed. por Julian H. Franklin. University Press.

Borba, V. (2014). Fronteiras e faixa de fronteira: expansionismo, limites e defesa. Historia, 4 (2), 59 - 78. https://periodicos.furg.br/hist/article/view/4131

Brasil. (1988). Constituição da República Federativa do BrasilSenado Federal. http://www.planalto.gov.br/ccivil_03/constituicao/constituicao.htm.

Brasil. (1999). Programa de Desenvolvimento Social da Faixa de Fronteira (PDSFF). 
Brasil. (2005). Decreto no 5.484. Aprova a Política de Defesa Nacional, e dá outras providências. http://www.planalto.gov.br/ccivil_03/_ato20072010/2008/Decreto/D6703.htm.

Brasil. (2012). Ministério da Defesa. Estratégia Nacional de Defesa. https://www.defesa.gov.br/arquivos/2012/mes07/end.pdf.

Brasil. (2015). Tribunal de Contas da União. Relatório de auditoria operacional: avaliação de governança de políticas públicas: fortalecimento da faixa de fronteira. https://portal.tcu.gov.br/biblioteca-digital/auditoria-operacional-para-avaliacao-da-governanca-nas-politicas-publicas-de-fortalecimento-da-faixa-defronteira-participacao-capacidade-organizacional-e-recursos-coordenacao-e-coerencia.htm.

Brasil. (2016). Ministério da Justiça. Plano Estratégico de Fronteiras e a Estratégia Nacional de Segurança Pública nas Fronteiras. http://www.justica.gov.br/sua-seguranca/seguranca-publica/analise-e-pesquisa/download/outras_publicacoes/pagina-3/mapeamento-das-politicas-federais-naff.pdf.

Brasil. (2019). Ministério da Integração Nacional. Coordenadoria para Desenvolvimento e Integração da Faixa de Fronteira. https://www.gov.br/mdr/ptbr/assuntos/desenvolvimento-regional/comissao-permanente-para-o-desenvolvimento-e-a-integracao-da-faixa-de-fronteira.

Brasil. (2019). Ministério da Defesa. Programa Calha Norte. http://calhanorte.defesa.gov.br/videos.html.

Bresser-Pereira, L. C. Estado, Estado-nação e formas de intermediação política. Lua Nova: Revista de Cultura e Política, 100, 155185https://doi.org/10.1590/0102-155185/100.

Burgardt, V. H. (2012). A nação nas fronteiras longínquas: o sentimento nacional dos pampas ao lavrado. In: Bento, F. R. (Org.) Fronteiras em Movimento. (103-121). Paco Editorial.

Carneiro, C. \& Ruckert, A. A. (2015). A Gestão Contemporânea das Fronteiras do Brasil: Defesa e Separação X Cooperação e Integração. Anais do XVI ENANPUR, 16(1). http://anais.anpur.org.br/index.php/anaisenanpur/issue/view/5.

Costa, M. K. B. da. (2017). Políticas de Segurança e Defesa da Fronteira Brasileira no Contexto de Integração Regional: os casos das fronteiras Brasil-Paraguai e Brasil-Uruguai. Brasília. Dissertação de Mestrado em Política Internacional da Universidade de Brasília (PPGRI - UnB). http://apps.unesp.br/renee/documento/imagens/m11_u48_12122017-20-06-31.pdf.

Costa, M. K. B. da. \& Neves, A. J. das. (2018). Soberania e Fronteira, dois Conceitos de duas Dimensões: Diplomacia, Defesa e Segurança na Fronteira entre Brasil e Paraguai. Revista de Iniciação Científica em Relações Internacionais, 6(11), 22-48. https://doi.org/10.22478/ufpb.2318-9452.2018v6n11.41230.

Costa, W. M. da. (1991). O Estado e as políticas territoriais no Brasil. (3a ed.), Contexto.

Denzin, N. K \& Lincoln, I. (2006). O planejamento da pesquisa qualitativa: teorias e abordagens. Artmed.

Durkheim, É. (1996). Le regole del método sociológico. Edzioni di Comunitá.

Farinha, M. J. U. S. \& Bernardo L. V. M \& Lima, M. S. A de \& Goettert, J. D. (2020). Considerações referentes às interações populares realizadas na fronteira do Brasil com o Paraguai e a Argentina. Research, Society and Development, 9(8). http://dx.doi.org/10.33448/rsd-v9i8.6131.

Ferrari, M. (2011). Interações transfronteiriças na zona de fronteira Brasil-Argentina. In Tese (Doutorado em Geografia). Universidade Federal de Santa Catarina. UFSC.

Garcia, F. C. (2010). Fronteira iluminada: história do povoamento, conquista e limites do Rio Grande do Sul a partir do Tratado de Tordesilhas. Sulina.

Gil, A. C. (2008). Como elaborar projetos de pesquisa. (4a ed.), Atlas.

Gil, A. C. (2014). Métodos e Técnicas de Pesquisa Social. (6a ed.), Atlas.

Granato, L. \& Batista I. R. (2018). Regionalismo e desenvolvimento na América do Sul. Revista Debates, 12(2), 201-222, maio/ago. https://doi.org/10.22456/1982-5269.83784.

Grimson, A. (2000). El puente que separó dos orillas: notas para una crítica del esencialismo de la hermandad. In: Gonzales, J. A. \& Grimson, A. (Org.) Fronteras, naciones e identidades: La periferia como centro. Buenos Aires: Ciccus-La Crujía.

Hall, S. (2001). A identidade cultural na pós-modernidade. (6a ed.), DP\&A Editora.

Hobsbawm, E. \& Ranger, T. (1995). A invenção das tradições. Paz e Terra.

Mann, M. (1992). O poder autônomo do Estado: suas origens, mecanismos e resultados: In Hall, J. (Org.) Os Estados na história. Imago.

Meira Mattos, C. de. (1990). A Geopolítica e a Teoria de Fronteiras. Editora Bibliex.

Minayo, M. C. S. (1994). Ciência, técnica e arte: o desafio da pesquisa social. In: Minayo, M. C. S.(Org.). Pesquisa social: teoria, método e criatividade. (18a ed.), Vozes.

Miyamoto, S. (1995). Geopolítica e poder no Brasil. Papirus.

Neves, A.J. das \& Silva, J.C. da \& Monteiro, J.C.do R. (Org.). (2016). Mapeamento das políticas públicas federais nas fronteiras: interfaces com o Plano Estratégico de Fronteiras e a Estratégia Nacional de Segurança Pública nas Fronteiras. Ministério da Justiça. https://www.idesf.org.br/wpcontent/uploads/2020/10/mapeamento-das-politicas-federais-na-ff.pdf. 
Research, Society and Development, v. 10, n. 9, e13410917950, 2021

(CC BY 4.0) | ISSN 2525-3409 | DOI: http://dx.doi.org/10.33448/rsd-v10i9.17950

Nunes, M. (2017). Dinâmicas transfronteiriças e o avanço da violência na fronteira sul-mato-grossense. In: Boletim Regional, Urbano e Ambiental - IPEA. 16, 31-38, https://www.ipea.gov.br/portal/images/stories/PDFs/boletim_regional/170531_bru_16_ensaio03.pdf.

Rego Monteiro, L. C. (2014). Segurança na América do Sul: a construção regional e a experiência colombiana. Tese de Doutorado/PPGG. Rio de Janeiro: UFRJ.

Resende. F. C. F. (2018). As Políticas de Segurança e Defesa para a Fronteira Brasileira como Estratégia Territorial Estatal: uma abordagem interinstitucional de seu processo decisório. Tese (Doutorado) Universidade Federal do Rio Grande do Sul, Instituto de Geociências, Programa de Pós-Graduação em Geografia, Porto Alegre.

Rey, F. L.G. (2005). O valor heurístico da subjetividade na investigação psicológica. In: Rey, F. L.G. (org.). Subjetividade, complexidade e pesquisa em Psicologia. São Paulo, Thomson.

Rocha, F. S. (2019). A Fronteira no Plural: metáforas da região trinacional Brasil-Paraguai-Argentina. In: Muniz, C. M. S. L. \& Soares, J. A.(Orgs.). O Mundo da Fronteira: reflexões a partir da fronteira trinacional: Brasil, Paraguai e Argentina. CRV,1.

Scherma, M. A. (2015a). As Fronteiras nas Relações Internacionais. In: Prado, H. S. de A. \& Neto T. E. (Org.) Fronteiras e relações internacionais. Curitiba: Íthala, 13-35.

Scherma, M. A. (2015b). As políticas brasileiras para a Faixa de Fronteira: um olhar a partir das relações internacionais. Tese (doutorado) - Universidade Estadual de Campinas, Instituto de Filosofia e Ciências Humanas, Campinas, SP. http://www.repositorio.unicamp.br/handle/REPOSIP/281269.

Scherma, M. A. (2018). Políticas de Defesa e Segurança para as Fronteiras nos Governos Lula e Dilma. Boletim de Economia e Política Internacional - IPEA 22, https://www.ipea.gov.br/portal/images/stories/PDFs/boletim_internacional/160628_boletim_internacional_22_art05.pdf.

Silva, A. F. da, \& Lalane, J. B. (2019). Migração haitiana e direitos humanos: o acesso à saúde pública em região de fronteira no Brasil. Research, Society and Development, 8(9), e05891248. https://doi.org/10.33448/rsd-v8i9.1248.

Silva, A. F. \& Pasquali, D. (2016). Migração e hábitos alimentares em ambientes educacionais: o caso da Tríplice Fronteira. Educere et Educare, 11(1).

Silva, A. F. \& Procópio C. E. P. (2019). Cristianismos em região de fronteira: trânsitos, tensões e reconfigurações religiosas. Revista Tomo, 34, 159-188, https://doi.org/10.21669/tomo.v0i34.10236.

Silva, A. L. R. \& Svartman, E. M. (2019). Inserção Internacional da Argentina e do Brasil: desafios da política externa e de defesa. Editora da UFRGS.

Silva, M. L. da \& Tourinho H. L. Z. (2018). Território, territorialidade e fronteira: o problema dos limites municipais e seus desdobramentos em Belém/PA. Revista Brasileira de Gestão Urbana, 9 (1), 96-109, https://doi.org/10.1590/2175-3369.009.001.AO09.

Tilly, C. (1996). Coerção, capital e estados europeus. Editora Edusp.

Weber, M. (2009). Economia e sociedade. Editora da UNB. 